\title{
Model Persamaan Struktural untuk Menganalisis Indikator Kesejahteraan Rumah Tangga
}

\author{
Achi Rinaldi \\ Universitas Islam Negeri Raden Intan Lampung. Jalan Endro Suratmin, Sukarame, Bandar \\ Lampung 35133, Indonesia. \\ * Corresponding Author. E-mail: achi@radenintan.ac.id
}

\begin{abstract}
Abstrak
Kesejahteraan merupakan hal penting yang menjadi perhatian semua negara di dunia, termasuk Indonesia. Kesejahteraan tidak hanya diukur secara material tetapi juga diukur secara rohani. Secara material, kesejahteraan diukur dari kekayaan yang dimiliki seseorang, kesehatan, gizi, pendidikan, aset, perumahan, dan hak-hak tertentu dalam masyarakat. Sedangkan secara rohani kesejahteraan diukur dari kebahagiaan yang dirasakan. Penelitian ini membahas penerapan model persamaan struktural untuk mengkaji keterkaitan antar indikator kesejahteraan di Provinsi Jawa Tengah. Model yang dibangun menempatkan pendidikan dan pekerjaan sebagai peubah laten eksogen, sedangkan kesejahteraan obyektif dan kesejahteraan subyektif sebagai peubah laten endogen. Data yang digunakan untuk mendukung analisis bersumber dari BPS, hasil Survei Sosial Ekonomi Nasional KOR dan MSBP 2012, dengan ukuran sampel 6730 pengamatan. Hasil pemodelan didapat model yang cukup layak untuk menjelaskan keragaman data, yang ditunjukkan oleh nilai GFI 0.97, AGFI 0.96, RMSEA 0.039, dan RMSR 0.072. Hasil analisis menunjukkan pendidikan dan pekerjaan memiliki pengaruh langsung terhadap kesejahteraan obyektif dan pengaruh tak langsung terhadap kesejahteraan subyektif. Pengaruh pendidikan terhadap tingkat kesejahteraan lebih tinggi dibandingkan pengaruh pekerjaan.
\end{abstract}

Kata kunci: peubah laten, indikator, maximum likelihood, GFI, AGFI, RMSEA, RMSR.

\begin{abstract}
Welfare is an important thing that concerns all countries in the world, including Indonesia. Welfare is not only measured materially but also spiritually measured. Materially, welfare is measured by one's wealth, health, nutrition, education, assets, housing, and certain rights in society. While spiritually well-being is measured by perceived happiness. This study discusses the application of the structural equation model to examine the relationship between welfare indicators in Central Java Province. The model-built places education and employment as exogenous latent variables, while objective well-being and subjective well-being are endogenous latent variables. The data used to support the analysis were sourced from BPS, the results of the 2012 KOR National Social Economic Survey and MSBP, with a sample size of 6730 observations. The modeling results obtained by the model are quite feasible to explain the diversity of data, which is indicated by the value of GFI 0.97, AGFI 0.96, RMSEA 0.039, and RMSR 0.072. The analysis shows that education and employment have a direct influence on objective well-being and an indirect effect on subjective well-being. The effect of education on the level of welfare is higher than the effect of work.
\end{abstract}

Keywords: latent variable, indicator, maximum likelihood, GFI, AGFI, RMSEA, RMSR. 


\section{PENDAHULUAN}

Kesejahteraan merupakan hal penting yang menjadi perhatian semua negara di dunia, termasuk Indonesia. Bahkan dalam pembukaan UUD 1945 secara tegas dinyatakan bahwa kesejahteraan merupakan tujuan akhir dari pembentukan negara Indonesia. Dalam bidang ekonomi, kinerja pembangunan dalam meraih kesejahteraan diukur berdasarkan produk domestik bruto (PDB) dan tingkat pertumbuhannya. Namun, sebagai ukuran keberhasilan pembangunan, PDB mempunyai kelemahan yaitu tingginya nilai PDB tidak menjamin tingginya tingkat kesejahteraan masyarakat suatu negara.

Dalam rangka mewujudkan masyarakat yang sejahtera, maka salah satu upaya yang dapat dilakukan adalah melalui identifikasi secara tepat faktorfaktor yang berpengaruh terhadap kesejahteraan. Identifikasi variabel merupakan hal yang sangat krusial untuk menentukan langkah pemodelan ke depannya (Rinaldi et al., 2018) Dalam lingkup rumah tangga, kesejahteraan suatu rumah tangga umumnya dipengaruhi oleh kondisi internal rumah tangga, meliputi pendidikan, pekerjaan (ketenagakerjaan), ekonomi, jumlah anggota rumah tangga, dan lain-lain yang dapat di jelaskan secara matematis dampak dan pengaruhnya (Darmani \& Renaldi, 2018). Namun dari faktor-faktor yang mempengaruhi kesejahteraan tersebut, faktor pendidikan dan pekerjaan dinilai memiliki pengaruh yang cukup menentukan terhadap kesejahteraan. Pengaruh yang ada antar variabel ini pun dapat dibangun melalui hubungan parsial dan juga simultan (Syazali et al., 2019).

Sementara itu, dari sisi alat ukur, kesejahteraan tidak hanya diukur secara material, tetapi juga secara rohani (Bappenas, 2010). Secara material, kesejahteraan didefinisikan sebagai kemampuan untuk memenuhi kebutuhan komoditas secara umum. Seseorang dikatakan sejahtera atau memiliki kemampuan ekonomi yang lebih baik jika dia memiliki kemampuan yang lebih besar dalam menggunakan sumber daya (kekayaan) yang dimilikinya, World Bank Institute dan BPS (2002). Lebih lanjut disebutkan, kesejahteraan dapat diukur dari kekayaan yang dimiliki seseorang, kesehatan, gizi, pendidikan, aset, perumahan, dan hak-hak tertentu dalam masyarakat. Dari kedua konsep ukuran kesejahteraan tersebut, dapat disarikan bahwa secara garis besar ada dua ukuran kesejahteraan yaitu kesejahteraan obyektif yang diukur secara material dan kesejahteraan subyektif yang diukur secara rohaniah (tidak secara material).

Pendidikan, pekerjaan, kesejahteraan obyektif, dan kesejahteraan subyektif merupakan peubah-peubah yang tidak dapat diukur secara langsung (peubah laten), tetapi diukur melalui indikator-indikator pengukurnya. Oleh karena itu, untuk menganalisis antar peubah (laten) tersebut serta melihat keterkaitannya dengan indikatorindikator pengukurnya digunakan model persamaan struktural (structural equation models).

\section{METODE}

Penelitian ini menggunakan metode penelitian kuantitatif melalui pemodelan statistik yang disebut model persamaan struktural. Tahapan analisis diawali dengan pendugaan parameter model awal persamaan struktural. Kemudian dilanjutkan dengan pengujian signifikansi parameter model menggunakan statistik uji $\mathrm{T}$ dan evaluasi terhadap kelayakan model menggunakan statistik khi-kudrat, GFI, AGFI, RMSEA, dan RMSR. Jika model awal ini dinilai belum layak, langkah selanjutnya dilakukan modifikasi model dengan cara mengeluarkan indikator yang tidak nyata. Langkah berikutnya, dilakukan pengujian signifikansi parameter dan evaluasi kelayakan model 
modifikasi. Setelah diperoleh model yang memenuhi kelayakan berdasarkan statistik khi-kudrat, GFI, AGFI, RMSEA, dan RMSR, dilanjutkan dengan analisis keterkaitan antar peubah laten, termasuk keterkaitan laten dengan indikator pengukurnya.

Bentuk umum model persamaan struktural dapat dituliskan sebagai berikut:

$$
\eta=\mathrm{B} \eta+\Gamma \xi+\zeta
$$

dimana :

$\eta$ : vektor peubah laten endogen berukuran $\mathrm{m} \times \mathrm{l}$

B : matriks koefisien peubah endogen ( $\eta$ ) berukuran $\mathrm{m} \times \mathrm{m}$

$\Gamma$ : matriks koefisien peubah laten eksogen $(\xi)$ berukuran $\mathrm{m} \times \mathrm{n}$

$\xi \quad$ : peubah eksogen berukuran $\mathrm{n} \times 1$

$\zeta$ : vektor sisaan/galat acak hubungan antara $\eta$ dan $\xi$ berukuran $\mathrm{m} \times \mathrm{l}$

$m$ : banyaknya peubah laten endogen

$\mathrm{n}$ : banyaknya peubah laten eksogen

Terdapat dua persamaan yang digunakan untuk menjelaskan model pengukuran, yaitu model pengukuran untuk peubah y dan model pengukuran peubah x (Rinaldi, 2015). Kedua model pengukuran tersebut dapat dinyatakan : model pengukuran untuk y

$y=\Lambda_{y} \eta+\varepsilon$

model pengukuran untuk $\mathrm{x}$

$x=\Lambda_{x} \xi+\delta$

dimana :

y : vektor peubah endogen yang dapat diamati berukuran $\mathrm{p} \times \mathrm{l}$

$\mathrm{x}$ : vektor peubah eksogen yang dapat diamati berukuran q x l

$\Lambda_{y}$ : matriks koefisien regresi antara $\mathrm{y}$ dan $\eta$ berukuran $\mathrm{p} \times \mathrm{m}$

$\Lambda_{x}$ : matriks koefisien regresi antara $\mathrm{x}$ dan $\xi$ berukuran q x n

$\varepsilon$ : vektor sisaan pengukuran dari $\mathrm{y}$ berukuran $\mathrm{p} \times \mathrm{l}$ $\delta$ : vektor sisaan pengukuran dari $\mathrm{x}$ berukuran $\mathrm{q} x \mathrm{l}$

$\mathrm{p}$ : banyaknya indikator dari peubah laten endogen

q : banyaknya indikator dari peubah laten eksogen

Asumsi persamaan model struktural adalah : $\varepsilon$ tidak berkorelasi dengan $\eta, \delta$ tidak berkorelasi dengan $\xi$, dan $\varepsilon, \delta$, dan $\zeta$ saling bebas. Selain itu, data menyebar normal ganda.

Matrik ragam peragam dari indikator y dan $\mathrm{x}$ dapat dituliskan sebagai:

$\Sigma=\left[\begin{array}{ll}\Sigma_{y y} & \Sigma_{y x} \\ \Sigma_{x y} & \Sigma_{x x}\end{array}\right]$

dimana :

$\Sigma_{x x}$ : matriks koragam dari peubah $\mathrm{x}$

$$
=\Lambda_{x} \Phi \Lambda_{x}^{\prime}+\Theta_{\delta}
$$

$\Sigma_{y y}$ : matriks koragam dari peubah y

$$
=\quad \Lambda_{y} \mathrm{~A}\left(\Gamma \Phi \Gamma^{\prime}+\Psi\right) \mathrm{A}^{\prime} \Phi \Lambda_{y}^{\prime}+\Theta_{\varepsilon}
$$

dengan $\mathrm{A}=(\mathrm{I}-\mathrm{B})^{-1}$

$\Sigma_{y x}$ : matriks koragam dari peubah y dan $\mathrm{X}$

$$
\begin{aligned}
& =\Lambda_{y}(\mathrm{I}-\mathrm{B})^{-1} \Gamma \Phi \Lambda_{x} \\
& =\Sigma_{x y}^{\prime}
\end{aligned}
$$

Jadi matrik $\Sigma$ merupakan fungsi dari $\theta=\left\lfloor\Lambda_{x}, \Lambda_{y}, \mathrm{~B}, \Gamma, \Phi, \Psi, \Theta_{\delta}, \Theta_{\varepsilon}\right\rfloor$

mendefinisikan model persamaan struktural, ditulis sebagai :

$$
\begin{gathered}
\Sigma(\theta)= \\
{\left[\begin{array}{cc}
\Lambda_{y} \mathrm{~A}\left(\Gamma \Phi \Gamma^{\prime}+\Psi\right) \mathrm{A}^{\prime} \Phi \Lambda_{y}^{\prime}+\Theta_{\varepsilon} & \Lambda_{y} \mathrm{~A} \Gamma \Phi \Lambda_{x}^{\prime} \\
\Lambda_{x} \Phi \Gamma^{\prime} \mathrm{A}^{\prime} \Lambda_{y}^{\prime} & \Lambda_{x} \Phi \Lambda_{x}^{\prime}+\Theta_{\delta}
\end{array}\right]}
\end{gathered}
$$

Metode yang banyak digunakan untuk menduga parameter model persamaan struktural adalah metode kemungkinan maksimum (Maximum Likelihood, ML). Penduga ML diperoleh dengan meminimumkan fungsi :

$F_{M L}=\log |\Sigma(\theta)|+\operatorname{tr}\left(S \Sigma^{-1}(\theta)\right)-\log |S|-(p+q)$ dengan mengasumsikan bahwa $S$ dan $\Sigma(\theta)$ adalah matriks definit potitif atau matriks non singular. Pada metode ML diasumsikan bahwa peubah indikator 
adalah peubah yang datanya menyebar normal ganda sehingga akan menghasilkan penduga kemungkinan maksimum yang efisien untuk ukuran contoh yang cukup besar, bahkan untuk sebaran ekstrim sekalipun (Rinaldi, 2016). Menurut Bollen (1989), penduga ML mempunyai sifat-sifat penting, yaitu : tak bias secara asimtotik (ada kemungkinan berbias pada ukuran contoh kecil, konsisten, efisien secara asimtotik, invariant terhadap skala pengukuran (satuan pengukuran tidak mempengaruhi nilai dugaan parameter model).

Dalam analisis model struktural, tidak ada alat uji statistik tunggal untuk mengukur atau menguji hipotesis mengenai model (Ferdinand A., 2000). Ada beberapa uji statistik yang dapat digunakan untuk menguji kelayakan model :

1. Uji Kebaikan Suai Chi-Kuadrat $\left(\chi^{2}\right)$

Uji kebaikan Suai Chi-Kuadrat merupakan pengujian seberapa dekat matriks hasil dugaan terhadap matriks data asal. Hipotesi dari uji adalah :

$H_{0}: \Sigma=\Sigma(\theta)$ lawan $H_{1}: \Sigma \neq \Sigma(\theta)$

dengan $\Sigma$ adalah matriks input, sedangkan $\Sigma(\theta)$ merupakan matriks dugaan. Dalam hal ini, $H_{0}$ menyatakan bahwa matriks dugaan dari model persamaan struktural mampu mengepas data dengan baik, sedangkan $H_{1}$ sebaliknya. Uji Chi-Kudrat bersifat sensitif terhadap besarnya contoh, oleh karenanya bila ukuran contoh lebih besar dari 200 maka harus didampingi alat uji lainnya (Hair et al., 1998).

2. Root Mean Square Residual (RMSR)

RMSR merupakan ukuran rata-rata dari kuadrat sisaan yang digunakan untuk membandingkan kecocokan dua model hipotetik dalam mengepas data. Statistik RMSR didefinisikan sebagai:

$$
R M S R=\sqrt{\frac{\sum_{i=1}^{p+q} \sum_{j=1}^{i}\left(s_{i j}-\hat{\sigma}_{i j}\right)^{2}}{(p+q)(p+q+1) / 2}}
$$

dimana : $\mathrm{p}$ : banyaknya indikator dari peubah laten endogen

q : banyaknya indikator dari peubah laten eksogen

$s_{i j}$ : unsur matriks S

$\hat{\sigma}_{i j}$ : unsur matriks $\hat{\Sigma}$

3. Root Mean Square Error of Approximation (RMSEA)

RMSEA digunakan sebagai pendamping bagi statistik Kki-Kuadrat dalam menilai kelayakan suatu model. RMSE dirumuskan sebagai :

$$
R M S E A=\sqrt{\frac{\chi^{2}}{(n-1) d f}-\frac{d f}{(n-1) d f}}
$$

dimana :

$\chi^{2}$ : nilai Chi-kuadrat model

df : derajat bebas Chi-kuadrat

$\mathrm{n}$ : ukuran contoh

Dalam uji ini, nilai RMSEA merupakan ukuran ketidakcocokan model, sehingga diharapkan nilainya kecil. Nilai yang lebih kecil atau sama dengan 0.08 merupakan indeks untuk dapat diterimanya model.

4. Goodness of Fit Indeks(GFI)

GFI merupakan ukuran yang mirip dengan koefisien determinasi $\left(\mathrm{R}^{2}\right) \mathrm{di}$ dalam analisis regresi klasik, sebagai ukuran seberapa besar model mampu menjelaskan keragaman data. Rumus dari GFI adalah :

$$
G F I=1-\frac{\operatorname{tr}\left[\left(\hat{\Sigma}^{-1} S-1\right)^{2}\right]}{\operatorname{tr}\left[\left(\hat{\Sigma}^{-1} S\right)^{2}\right]}
$$

Dalam kriteria ini, tidak ada kriteria baku kapan suatu model dikatakan layak atau mampu menjelaskan data. Hanya saja, batas minimal 0.9 sering dijadikan patokan suatu model dikatakan layak (Hair et al., dalam Ferdinan, 2000).

5. Adjusted Goodness of Fit Indeks(AGFI) AGFI merupakan modifikasi dari GFI, dengan mengakomodasi derajat bebas model dengan model lain yang dibandingkan. Rumus dari AGFI adalah :

$$
A G F I=1-\left[\frac{k(k+1)}{2 d f}\right][1-G F I]
$$




\section{HASIL DAN PEMBAHASAN}

Hasil dugaan parameter dan diagram jalur dari model awal tersebut, seperti terlihat pada Gambar 1. Dari gambar tersebut, angka yang menyertai anak panah dari peubah laten ke indikator pengukurnya maupun dari peubah laten ke peubah laten lainnya menunjukkan koefisien regresi. Sedangkan angka yang menyertai anak panah menuju ke indikator yang bukan berasal dari peubah laten menyatakan ragam galat pengukuran.

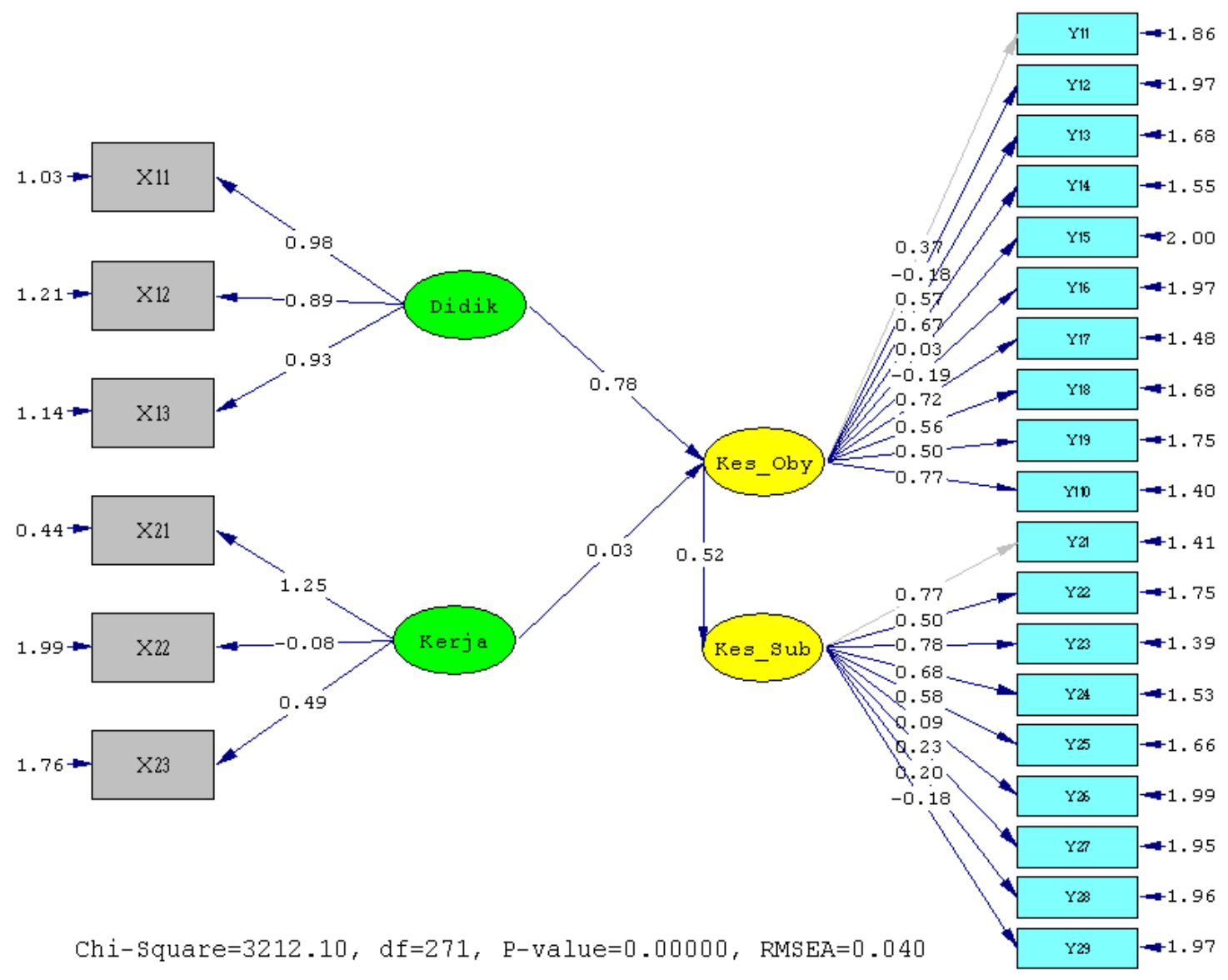

Gambar 1. Diagram Jalur Model Awal Persamaan Strukturalalur

Selanjutnya berdasarkan nilai Thitung dari dugaan parameter model (Tabel 1), diketahui bahwa indikator pengukur peubah laten pendidikan, pekerjaan, dan kesejahteraan subyektif semuanya berpengaruh nyata terhadap peubah laten yang diukurnya pada taraf
0.05. Sementara itu, indikator pengukur laten kesejahteraan obyektif, ada satu indikator yang tidak berpengaruh nyata pada taraf 0.05 , yaitu luas lantai per kapita $\left(Y_{15}\right)$. 
Desimal, 2(3), 2019 - 286

Achi Rinaldi

Tabel 1. Dugaan Parameter Model Pengukuran Awal

\begin{tabular}{|c|c|c|c|c|}
\hline \multirow{2}{*}{$\begin{array}{l}\text { Peubah Laten } \\
\text { Pendidikan }\end{array}$} & \multirow{2}{*}{$\begin{array}{c}\text { Peubah Indikator } \\
\text { X11 }\end{array}$} & \multirow{2}{*}{$\begin{array}{c}\text { Koef. } \lambda \\
0.98\end{array}$} & \multicolumn{2}{|c|}{ T-hitung } \\
\hline & & & 55.41 & * \\
\hline & $\mathrm{X} 12$ & 0.89 & 49.43 & $*$ \\
\hline & $\mathrm{X} 13$ & 0.93 & 51.95 & $*$ \\
\hline \multirow[t]{3}{*}{ Pekerjaan } & $\mathrm{X} 21$ & 1.25 & 22.10 & $*$ \\
\hline & $\mathrm{X} 22$ & 0.08 & -4.15 & $*$ \\
\hline & $\mathrm{X} 23$ & 0.49 & 17.98 & $*$ \\
\hline \multirow[t]{10}{*}{$\begin{array}{l}\text { Kesejahteraan } \\
\text { Obyektif }\end{array}$} & Y11 & 0.37 & & $*$ \\
\hline & Y12 & -0.18 & -8.26 & $*$ \\
\hline & Y13 & 0.57 & 16.17 & $*$ \\
\hline & Y14 & 0.67 & 16.95 & $*$ \\
\hline & Y15 & 0.03 & 1.71 & \\
\hline & Y16 & -0.19 & -8.38 & $*$ \\
\hline & Y17 & 0.72 & 17.25 & * \\
\hline & Y18 & 0.56 & 16.13 & $*$ \\
\hline & Y19 & 0.5 & 15.40 & $*$ \\
\hline & Y110 & 0.77 & 17.52 & $*$ \\
\hline \multirow[t]{9}{*}{$\begin{array}{l}\text { Kesejahteraan } \\
\text { Subyektif }\end{array}$} & $\mathrm{Y} 21$ & 0.77 & & $*$ \\
\hline & Y22 & 0.5 & 20.31 & $*$ \\
\hline & Y23 & 0.78 & 26.66 & $*$ \\
\hline & Y24 & 0.68 & 24.99 & * \\
\hline & Y25 & 0.58 & 22.62 & $*$ \\
\hline & Y26 & 0.09 & 4.11 & $*$ \\
\hline & Y27 & 0.23 & 10.33 & $*$ \\
\hline & Y28 & 0.2 & 9.04 & $*$ \\
\hline & Y29 & -0.18 & -8.23 & $*$ \\
\hline
\end{tabular}

*:signifikan

Hasil evaluasi kelayakan terhadap model awal persamaan struktural (Tabel 2), statistik Chi kuadrat sebesar 3212,1 dan nyata pada taraf 0.05 , menunjukkan bahwa keadaan empiris data tidak sesuai dengan model awal yang dihipotesiskan. Namun statistik Chi kuadrat ini cukup sensitif terhadap besarnya ukuran contoh yang sebesar 6730 pengamatan. Oleh karena itu, sebagai pendamping digunakan statistik RMSEA dan RMSR yang mengukur ketidakcocokan model. Dari kedua ukuran statistik ini, model awal yang dihipotesiskan dinilai memiliki ketidakcocokan yang rendah, masing- masing nilainya kurang dari 0.08. Ini mengindikasikan bahwa model awal tersebut telah memiliki tingkat kecocokan yang diharapkan. Tingkat kecocokan model awal ini juga didukung oleh statistik GFI dan AGFI yang masingmasing nilainya sebesar 0.96, yang mengindikasikan bahwa model sudah mampu menjelaskan 96 persen keragaman data.

Tabel 2. Evaluasi Kelayakan Model

\begin{tabular}{cc} 
Kriteria & Nilai \\
Khi Kuadrat & $3212.1(\mathrm{p}$-value $=0.00, \mathrm{df}=271)$ \\
\hline
\end{tabular}




\begin{tabular}{ll}
\hline GFI & 0.960 \\
AGFI & 0.960 \\
RMSEA & 0.040 \\
RMSR & 0.074 \\
\hline
\end{tabular}

\section{SIMPULAN DAN SARAN}

Berdasarkan hasil dan pembahasan, dapat ditarik kesimpulan bahwa model persamaan struktural dengan 24 indikator dinilai memiliki kriteria kelayakan model sangat baik. Ini ditunjukkan oleh nilai GFI 0.97, AGFI 0.96 yang keduanya lebih besar dari 0.9. Selain itu, model ini juga memiliki RMSEA dan RMSR yang cukup kecil, masing-masing sebesar 0.039 dan 0.072 .

Pendidikan memiliki pengaruh langsung terhadap tingkat kesejahteraan obyektif rumah tangga sebesar 0.78 , lebih tinggi dibandingkan pengaruh pekerjaan 0.04 .

Pengaruh tak langsung pendidikan terhadap kesejahteraan subyektif sebesar 0.41 , sedangkan pengaruh tak langsung pekerjaan terhadap kesejahteraan subyektif sebesar 0.02 .

Untuk meningkatkan kesejahteraan rumah tangga, salah satu program pemerintah yang perlu mendapat perhatian adalah peningkatan jenjang pendidikan kepala rumah tangga, yaitu minimal tamat SLTA/sederajat.

Pada laten pekerjaan, faktor lapangan pekerjaan utama kepala rumah tangga khususnya non pertanian memiliki pengaruh yang paling tinggi terhadap kesejahteraan rumah tangga, baik obyektif dan subyektif.

Dalam penelitian lebih lanjut, perlu dikaji secara lebih mendalam indikatorindikator yang berpengaruh terhadap kesejahteraan rumah tangga, sehingga dapat diperoleh gambaran yang lengkap dan menyeluruh tentang faktor-faktor yang berpengaruh terhadap kesejahteraan rumah tangga.

\section{DAFTAR PUSTAKA}

Bappenas. (2010). Peraturan Presiden Republik Indonesia No. 5 Tahun 2010 tentang Rencana Pembangunan Jangka Menengah Nasional Tahun 2010-2014, Buku I. Jakarta.

Bollen KA. (1989). Structural Equations with Latent Variables, New York : J. Wiley.

Darmani, J. W., \& Renaldi, A. (2018). Analisis Kemampuan Pemecahan Masalah Matematis: Dampak Model Pembelajaran Reciprocal Teaching Dengan Fieldtrip. Desimal: Jurnal Matematika, 1(3), 373-380.

Ferdinand, A. (2000). Structural Equation Modelling dalam Penelitian Managemen. Universitas Diponegoro, Semarang.

Hair JF., Anderson RE., Tatham RL., and Black WC. (1998). Multivariate Data Analysis, Fifth Edition. New Jersey: Prentice Hall, Inc.

Joreskog KG and Sorbon. (1996). LISREL 8 : User's Reference Guide, Scientific Software International, Inc. Chicago.

World Bank Institute dan BPS. (2002). Dasar-dasar Analisis Kemiskinan, Buku Panduan Basic Poverty Measurement and Diagnostics Course. Jakarta.

Rinaldi, A. (2015). Aplikasi Model Persamaan Struktural Pada Program R (Studi Kasus Data Pengukuran Kecerdasan). Al-Jabar: Jurnal Pendidikan Matematika, 6(1), 1-12.

Rinaldi, A. (2016). Sebaran Generalized Extreme Value (GEV) dan Generalized Pareto (GP) untuk Pendugaan Curah Hujan Ekstrim di Wilayah DKI Jakarta. Al-Jabar: Jurnal Pendidikan Matematika, 7(1), 75-84.

Rinaldi, A., Djuraidah, A., Wigena, A. H., Mangku, I. W., \& Gunawan, D. (2018, November). Identification of Extreme Rainfall Pattern Using Extremogram in West Java. In IOP 
Desimal, 2(3), 2019 - 288

Achi Rinaldi

Conference Series: Earth and Environmental Science (Vol. 187, No. 1, p. 012064). IOP Publishing.

Syazali, M., Putra, F., Rinaldi, A., Utami, L., Widayanti, W., Umam, R., \& Jermsittiparsert, K. (2019). Partial correlation analysis using multiple linear regression: Impact on business environment of digital marketing interest in the era of industrial revolution 4.0. Management Science Letters, 9(11), 1875-1886. 